\title{
Midkine Is Part of the Antibacterial Activity Released at the Surface of Differentiated Bronchial Epithelial Cells
}

\author{
Sara L. Nordin ${ }^{a}$ Cecilia Andersson ${ }^{a}$ Leif Bjermer ${ }^{a} \quad$ Anders Bjartell ${ }^{c}$ \\ Matthias Mörgelin ${ }^{b} \quad$ Arne Egesten $^{a}$
}

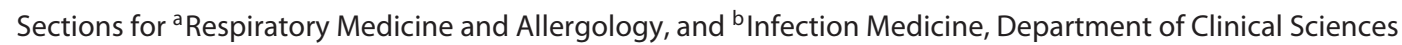
Lund, Lund University, Skåne University Hospital, Lund, and ' Division of Urological Cancers, Department of Clinical Sciences Malmö, Lund University, Skåne University Hospital, Malmö, Sweden

\section{Key Words}

Midkine $\cdot$ Bronchial epithelial cells $\cdot$ Host defense .

Infection · Bacteria

\begin{abstract}
To resist infections, robust defense mechanisms of the airways are essential. Retinoic acid promotes differentiation and maintains the phenotypic characteristics of bronchial epithelium. In addition, it induces the expression of the antibacterial growth factor midkine (MK). In the present study, we explored the expression and antibacterial activity of MK in an airway context. MK was detected in bronchial epithelial cells of large airways and type 2 pneumocytes of normal lungs by immunohistochemistry. Immunoelectron microscopy revealed a surface-associated distribution, both on the ciliated apical and basolateral sides, and MK was detected in sputum obtained from healthy individuals by ELISA. In vitro, MK killed the common respiratory pathogen Streptococcus pneumoniae at below micromolar concentrations, an activity retained in the presence of sodium chloride at physiological concentrations. The MK molecule consists of two domains with three anti-parallel $\beta$-sheets and a $\mathrm{COOH}$-terminal tail. Although both the $\mathrm{NH} 2$ - and $\mathrm{COOH}$-terminal domains alone showed antibacterial activity, the $\mathrm{COOH}$-terminal domain in-
\end{abstract}

cluding the tail region possessed higher bactericidal activity, i.e. in the order of the holoprotein. Retinoic acid-induced differentiation of primary bronchial epithelial cells, using an airliquid interface system, revealed bactericidal activity in the apical airway surface liquid, an activity that was reduced after immunoprecipitation of MK. This study shows that airway epithelial cells of large airways and alveoli have a constitutive production of MK that is part of the bactericidal activity present in the air surface liquid, at least in vitro, and may thus be an important part of this arm of airway host defense.

Copyright $\odot 2013$ S. Karger AG, Basel

\section{Introduction}

Potential pathogens present in the environment are inhaled with every breath. Dependent on the environment, the ambient air contains $10^{2}-10^{5}$ colony-forming units of bacteria per $\mathrm{m}^{3}$ [1]. Constitutive host defense mechanisms include several arms to eradicate potentially infesting microbes including mucociliary clearance, secretory IgA, surfactant proteins (e.g., SP-A and SP-D) and alveolar macrophages [2]. Airway epithelium also constitutively produces the antimicrobial protein (AMP) lysozyme, first described by Sir Alexander Fleming [3] in

\section{KARGER}

E-Mail karger@karger.com

www.karger.com/jin
(C) 2013 S. Karger AG, Basel

$1662-811 \mathrm{X} / 13 / 0055-0519 \$ 38.00 / 0$
Dr. Arne Egesten

Department of Clinical Sciences Lund, Lund University

Skåne University Hospital, BMC B14

Tornavägen 10, SE-221 84 Lund (Sweden)

E-Mail Arne.Egesten@med.lu.se 
1922, lactoferrin and secretory leukocyte proteinase inhibitor [3-6]. Upon infection, the inflammatory response causes recruitment of leukocytes and induces the expression of a plethora of AMPs [7]. These include the cathelicidin hCAP-18/LL-37 and $\beta$-defensins [8-12]. The most important bacterial threat to the airways is Streptococcus pneumoniae. This is an encapsulated Gram-positive bacterium with 91 different capsules or serotypes identified so far. S. pneumoniae is a common colonizer of the nasopharynx in children, but also the most common cause of community-acquired pneumonia and, at times, causes invasive pneumococcal diseases (i.e. sepsis and meningitis), killing more than two million people in the world every year and leaving severe sequelae in many children [13]. For quite some time, it has been recognized that vitamin $\mathrm{A}$ and its derivatives are important for the differentiation of the pulmonary tree during embryogenesis [14]. More recently, vitamin A (retinol $\mathrm{R}^{2}$ and its esters), the precursor of retinoic acid (RA), has been demonstrated to be crucial for, among other things, differentiation and maintaining the phenotypic characteristics of the ciliated columnar epithelium of the bronchi, mucus production and the production of surfactant proteins [15]. Recently, we showed that midkine (MK) and pleiotrophin, the two members of a family of heparin-binding growth factors with RA-responsive elements in their promoter region, have strong antibacterial activity in vitro $[16,17]$. The present study was set out to investigate whether MK is produced by airway epithelial cells in vivo and in vitro and whether it may play a role as a host defense molecule in this context.

\section{Materials and Methods}

\section{Chemicals and Reagents}

Recombinant human MK was from PeproTech (London, UK). According to the manufacturer, the purity of MK was $>98 \%$, as determined by SDS-PAGE and HPLC analyses. Confirmation of the correct tertiary conformation and insertion of disulfide bonds was previously described [17-19]. The folded C-domain (amino acids 84-126) and C-terminal half domain (amino acids 82-143) of MK, synthesized as described, were generously supplied by Dr. Tatsuya Inui, Peptide Institute, Osaka, Japan [20, 21]. The folded N-terminal MK domain (amino acids 21-81) was purchased from Bachem, Bubendorf, Switzerland.

\section{Patients}

Transbronchial biopsies were obtained from 8 healthy, neversmoking and nonatopic subjects (5 males and 3 females with no respiratory symptoms; mean age 23 years, range 21-39; normal lung function as assessed by measurement of forced expiratory volume in $1 \mathrm{~s}$ using spirometry, negative skin prick test to grass or tree pollen, cat, dog, horse, mould or house dust mite; and not hyperresponsive to metacholine). From each of the 8 subjects, central airway biopsies ( $\mathrm{n}=5$ per patient) and transbronchial biopsies ( $n=5$ per patient) were collected from the segmental or subsegmental carina in the right lower and upper lobes and the alveolar parenchyma during a study period from December 2008 to June 2009 at the Department of Respiratory Medicine, Lund University Hospital. Bronchoscopy was performed after local anesthesia with a flexible bronchoscope (Olympus IT160, Tokyo, Japan). All subjects were without upper respiratory tract infections within 3 weeks prior to the investigation. Induced sputum from 4 healthy individuals was obtained after inhalation of nebulized sodium chloride. All subjects gave their written informed consent to participate in the study, which was approved by the ethics committee in Lund (LU412-03).

\section{In situ Hybridization}

To detect MK gene expression, a DIG-labeled RNA probe with the sequence AACTCCTTCTTCCAGTTGCA was used (Exiqon, Vedbaek, Denmark). A scrambled oligonucleotide with the sequence GTGTAACACGTCTATACGCCCA was used as control. In situ hybridization was performed essentially as described [22]. Paraffin-embedded lung tissue was sectioned $(4 \mu \mathrm{m})$, dried for $2 \mathrm{~h}$ at $65^{\circ} \mathrm{C}$ and mounted on SuperFrost plus slides (Menzel-Gläser, Braunschweig, Germany) under RNase-free conditions. The sections were deparaffinized in xylene and rehydrated, after which they were first treated with $0.2 \mathrm{M} \mathrm{HCl}$ to abolish endogenous enzyme activity and then digested with proteinase $\mathrm{K}(20 \mu \mathrm{g} / \mathrm{ml}$ in 20 $\mathrm{mM}$ Tris- $\mathrm{HCl}, 2 \mathrm{mM} \mathrm{CaCl}_{2}, \mathrm{pH} 7.5$ ) for $25 \mathrm{~min}$ at $37^{\circ} \mathrm{C}$. The slides were then incubated in $0.25 \%$ acetic anhydride containing $0.1 \mathrm{M}$ triethanolamine and $0.15 \mathrm{M} \mathrm{NaCl}$ for $10 \mathrm{~min}$ and then equilibrated in $2 \times$ standard saline citrate (SSC; $1 \times$ SSC contains $150 \mathrm{mM} \mathrm{NaCl}$ and $15 \mathrm{~mm}$ sodium citrate, $\mathrm{pH}$ 7.0). After prehybridization with 40 $\mu \mathrm{l}$ of hybridization buffer containing $50 \%$ ( $\mathrm{vol} / \mathrm{vol}$ ) formamide, $10 \%$ dextran sulfate, $1 \times$ Denhardt's solution (BSA, polyvinyl pyrrolidone, and Ficoll, all at $0.2 \mathrm{mg} / \mathrm{ml}$ ), $4 \times \mathrm{SSC}$ and $0.4 \mathrm{mg} / \mathrm{ml}$ salmon sperm DNA at $85^{\circ} \mathrm{C}$ for $8 \mathrm{~min}$ and then at $42^{\circ} \mathrm{C}$ for $1 \mathrm{~h}$, the slides were hybridized with $40 \mu \mathrm{l}$ of $250-500 \mathrm{ng} / \mathrm{ml}$ in hybridization buffer, first for $8 \mathrm{~min}$ at $85^{\circ} \mathrm{C}$ and then for $16 \mathrm{~h}$ at $50^{\circ} \mathrm{C}$. After hybridization, the slides were washed in $1 \times \mathrm{SSC}$ at room temperature ( $5 \mathrm{~min}$, twice), $0.1 \times \mathrm{SSC}$ at $55^{\circ} \mathrm{C}(15 \mathrm{~min}, 4$ times), $1 \times \mathrm{SSC}$ at room temperature (10 min) and then equilibrated in TBS (100 mM Tris- $\mathrm{HCl}, 0.4 \mathrm{M} \mathrm{NaCl}, \mathrm{pH}$ 7.5). For detection of hybridization signals, tissue sections were first incubated in blocking reagent $(0.5 \%$, $\mathrm{wt} / \mathrm{vol}$, in TBS) for $1 \mathrm{~h}$ at room temperature, rinsed in TBS and subsequently incubated with anti-digoxigenin alkaline phosphatase conjugate (Roche, Bromma, Sweden) diluted 1:500 in TBS containing $0.5 \%$ (wt/vol) BSA for $1 \mathrm{~h}$ at room temperature. After washing in TBS, the sections were equilibrated in detection buffer (100 mM Tris- $\mathrm{HCl}$ containing $100 \mathrm{mM} \mathrm{NaCl}, 50 \mathrm{mM} \mathrm{MgCl}_{2}, \mathrm{pH}$ 9.5; $5 \mathrm{~min}$, twice) and developed in detection buffer containing $1 \mathrm{~mm}$ levamisol, $0.33 \mathrm{mg} / \mathrm{ml}$ nitro blue tetrazolium chloride and $0.167 \mathrm{mg} / \mathrm{ml}$ 5-bromo-4-chloro-3-indolyl phosphate.

\section{Immunohistochemistry}

Immediately after collection, biopsies were placed in $4 \%$ buffered formaldehyde, dehydrated, embedded in paraffin, and thin sections $(3 \mu \mathrm{m})$ were generated.

Single Staining of $M K$. A single staining protocol (EnVision ${ }^{\mathrm{TM}}$ Detection system, K5007; Dako, Glostrup, Denmark) was used for 
visualization of MK. Briefly, MK was detected by a rabbit polyclonal MK antibody (PeproTech) and secondary antibodies conjugated with peroxidase polymers. The immunohistochemistry protocols were performed using an automated immunohistochemistry robot (Autostainer ${ }^{\mathrm{TM}}$; Dako). Sections were stained with Mayer's hematoxylin for visualization of background tissue and were dehydrated in alcohol and xylene and mounted in Pertex ${ }^{\mathrm{TM}}$ mounting medium (Histolab, Göteborg, Sweden).

Double Staining of $M K$ and $S P-A$. After antigen retrieval and a blocking step (Protein Block X0909 ${ }^{\mathrm{TM}}$; Dako), sections were incubated over night in $4^{\circ} \mathrm{C}$ with rabbit $\mathrm{MK}$ antibody, and immunoreactivity was visualized after $1 \mathrm{~h}$ of incubation at room temperature with a goat anti-rabbit Alexa-Flour 555-conjugated secondary antibody (diluted 1:200; Molecular Probes, Eugene, Oreg., USA). SP-A was detected after $1 \mathrm{~h}$ of incubation at room temperature with a mouse anti-SPA (1:50; Dako) and visualized after incubation at room temperature for $1 \mathrm{~h}$ with an Alexa-Flour 488-conjugated goat anti-mouse secondary antibody (1:200; Molecular Probes). Nuclei were visualized using Hoechst 33342, and the sections were mounted in TBS/glycerin and frozen until quantification. For all immunohistochemical procedures, markers and tissues, staining was absent in sections using isotype-matched control antibodies at the same concentration as the primary antibodies (Dako).

\section{Electron Microscopy}

Tissue samples from healthy lungs were fixed in PBS containing $4 \%$ paraformaldehyde with $0.1 \%$ glutaraldehyde and prepared for immunostaining and transmission electron microscopy, as described $[23,24]$. In short, samples were incubated with the primary antibody and gold conjugated CNBr extracts (dilution 1:50 to $1: 100)$, followed by detection with a secondary antibody $(10 \mathrm{~nm}$ gold; Electron Microscopy Sciences, Fort Washington, Pa., USA; dilution 1:10 to $1: 20)$. Specimens were examined in a JEOL JEM 1230 transmission electron microscope (JEOL, Peabody, Mass., USA) at $60 \mathrm{kV}$ accelerating voltage. Images were recorded with a Gatan Multiscan 791 CCD camera. For scanning electron microscopy (SEM), bacteria were cultured to the mid-logarithmic phase, as described below. The bacteria were then incubated at $37^{\circ} \mathrm{C}$ for $1 \mathrm{~h}$ in buffer, with $1 \mu \mathrm{M} \mathrm{MK}$ or with rinsing fluid from the apical surface of bronchial epithelial cells cultured at an air liquid interface (ALI). To verify bacterial killing, part of the sample was used for the viable count assay described below. The remaining parts of the samples were processed for SEM. In short, $10 \mu$ of the incubation mixture (undiluted) was cut out and fixed in $2.5 \%$ ( $\mathrm{vol} / \mathrm{vol}$ ) glutaraldehyde, $0.15 \mathrm{M}$ sodium cacodylate overnight at room temperature and then washed with $0.15 \mathrm{M}$ sodium cacodylate. After fixation, samples were washed and dehydrated in alcohol at increasing concentrations $(2 \times 15$ min per step $)$, critical point dried, mounted on aluminium holders and covered with $20 \mathrm{~nm}$ of gold. Samples were examined in a XL30 FEG scanning electron microscope operated at an acceleration voltage of $5 \mathrm{kV}$ and a magnification of $\times 5,000$ to $\times 150,000$.

\section{Bacterial Strains and Growth Conditions}

The S. pneumoniae strain TIGR4 is a clinical encapsulated isolate of serotype 4 sequenced by the Institute for Genomic Research TIGR (ATCC BAA-334; Rockville, Md., USA; http://www.tigr. org) and the encapsulated serotype 3 strain A66 was from the National Collection of Type Cultures, London, UK. These strains were routinely grown in Todd-Hewitt broth (Difco/Becton and Dickinson, Franklin Lakes, N.J., USA) supplemented with $0.5 \%$ yeast extract liquid medium or on blood agar plates in $5 \% \mathrm{CO}_{2}$ and at $37^{\circ} \mathrm{C}$.

\section{Viable Count Assay}

All bacteria were cultivated to the mid-logarithmic phase (the optical density at $620 \mathrm{~nm}$ was 0.4 ) in broth, washed and diluted $(1: 1,000)$ in incubation buffer $(10 \mathrm{~mm}$ Tris- $\mathrm{HCl}$, containing $5 \mathrm{~mm}$ glucose, $\mathrm{pH} 7.4)$. Fifty microliters of bacteria $\left[10^{6}\right.$ colony-forming units $(\mathrm{CFU}) / \mathrm{ml}$ ] were incubated in the absence or presence of peptides at various concentrations $(0.01-3 \mu \mathrm{M})$ for $1 \mathrm{~h}$ at $37^{\circ} \mathrm{C}$. To quantify antibacterial activity, serial dilutions of the incubation mixtures were plated on blood agar plates, incubated overnight at $37^{\circ} \mathrm{C}$, and the number of CFU determined. In order to investigate the activity of $\mathrm{MK}$ in the presence of salt, the viable count assay was also performed after addition of different concentrations of sodium chloride to the incubation buffer (5-150 mM).

\section{Cell Culture}

Primary human bronchial epithelial cells (HBEC; $3 \mathrm{H}$ Biomedical, Uppsala, Sweden) were grown in bronchial epithelial cell growth medium (BEGM; 3H Biomedical) supplemented with BEGM bullet kit ( $3 \mathrm{H}$ Biomedical; according to the manufacturer containing hydrocortisone, human epidermal growth factor, epinephrine, transferrin, insulin, RA, and triiodothyronine), without antibiotics. The human alveolar type 2 pneumocyte-like epithelial cell line A549 (ATCC, Manassas, Va., USA) was grown in RPMI1640 GlutaMAX (Invitrogen) supplemented with 10\% FBS and 1\% penicillin-streptomycin (Sigma) at $37^{\circ} \mathrm{C}$ with $5 \% \mathrm{CO}_{2}$. The immortalized bronchial epithelial cell line BEAS-2B (ATCC) was grown in RPMI-1640 GlutaMAX supplemented with 10\% FBS and $1 \%$ penicillin-streptomycin (Sigma). The SV40-transformed bronchial epithelial cell line 16-HBE cells, a generous gift from Dr. C. Gruenert (University of California, San Francisco, Calif., USA), were grown in MEM GlutaMAX media (Invitrogen, Stockholm, Sweden) supplemented with $10 \%$ FBS and $1 \%$ penicillin-streptomycin (Sigma) at $37^{\circ} \mathrm{C}$ with $5 \% \mathrm{CO}_{2}$. Human pulmonary alveolar epithelial cells (HAEpiC) comprised of type 1 and type 2 pneumocytes $(3 \mathrm{H}$ Biomedical) were grown in poly-L-lysin (Sigma) coated flasks in alveolar epithelial cell medium with supplements (3H Biomedical). All cells were grown in flasks (T25; Nunc) until $90 \%$ confluence. Thereafter, the cells were washed with medium, and $5 \mathrm{ml}$ of fresh complete medium was added and the cells incubated for another $72 \mathrm{~h}$ when the medium was collected, stored at $-80^{\circ} \mathrm{C}$ and subsequently used in the MK ELISA.

\section{ALI Cell Culture}

Primary HBEC (3H Biomedical) were grown in BEGM supplemented with BEGM bullet kit $(3 \mathrm{H}$ Biomedicals) in a Transwell system (Corning HTS Transwell ${ }^{\circledR}, 24$-well permeable support, Sigma; $0.4 \mu \mathrm{m}$ pore size, $12 \mathrm{~mm}$ diameter, polyester). HBEC from frozen first-passage cells were thawed and cultured in a T75 flask with BEGM at $37^{\circ} \mathrm{C}$ in an atmosphere of $5 \% \mathrm{CO}_{2}$ and $95 \%$ relative humidity. The medium was changed every 2 days. When cultures reached $80-90 \%$ confluence, the medium was collected and used for MK ELISA and the cells were detached with trypsin and seeded at densities of $4 \times 10^{5} \mathrm{cells} / \mathrm{cm}^{2}$ on purecol $(1: 100 \mathrm{vol} / \mathrm{vol})$ coated Transwell inserts. Both the apical $(0.5 \mathrm{ml})$ and basolateral side $(1.5$ $\mathrm{ml}$ ) were filled with BEGM (supplemented with BEGM bullet kit). 
On day 3 , the medium on the apical side was removed and the cells were exposed to ambient conditions on this side. On the basolateral side, the medium, ALI medium, BEGM supplemented with bullet kit (3H Biomedical), BSA $(1.5 \mathrm{mg} / \mathrm{ml})$ and D-MEM (Invitrogen) supplemented with $1 \%$ MEM-Na-Pyr and $1 \%$ L-glutamin and $1 \%$ MEM NEA (50/50 w/w; Invitrogen) supplemented with $0.1 \%$ RA ( $0.1 \mathrm{mM}$; Sigma), was changed every day. $72 \mathrm{~h}$ before harvesting, the cells were rinsed and the medium used had no antibiotic added. After 24 days in ALI culture, the cells were harvested by rinsing the apical side with $100 \mu 10 \mathrm{mM}$ Tris- $\mathrm{HCl}$ (containing $5 \mathrm{~mm}$ glucose, $\mathrm{pH}$ 7.4) and collecting the rinsing fluid, the basolateral medium was collected and stored at $-80^{\circ} \mathrm{C}$ to be used for ELISA and viable count assay.

\section{MK ELISA}

ELISA to detect human MK in sputum, diluted air surface liquid and cell medium was performed using a human MK ELISA (PeproTech) according to the manufacturer's protocol. ELISA was used in the range from 64 to $4,000 \mathrm{pg} / \mathrm{ml}$. Samples were measured in triplicates.

\section{Immunoprecipitation}

The rinsing fluids, obtained from the apical side of the ALI cultures, were subjected to immunoprecipitation. In short, the rinsing fluids were either incubated with $4 \mu \mathrm{g}$ of affinity-purified polyclonal rabbit antibodies against MK (PeproTech) or incubated with preimmune rabbit IgG (PeproTech) for $4 \mathrm{~h}$ at $4^{\circ} \mathrm{C}$. Protein-G sepharose $(2 \mathrm{mg} / \mathrm{ml}$; GE Healthcare Biosciences, Uppsala, Sweden) was then added and incubated with the samples overnight at $4^{\circ} \mathrm{C}$ to precipitate the antibodies. Finally, the samples were centrifuged at 3,000 rpm for $5 \mathrm{~min}$ and the supernatants were collected and used in the viable count assay.

\section{Statistical Analysis and Calculations}

The statistical analysis was performed using KaleidaGraph (Synergy Software, Reading, Pa., USA). All data are presented as the mean \pm SD. Statistical significance was determined using Student's $t$ test for paired observations. Theoretical isolelectric point, net charge and molecular weights were calculated using the software tool ProtParam at the Swiss Institute for Bioinformatics (http://web.expasy.org/protparam).

\section{Results}

\section{Detection of $M K$ in Lung Tissue}

Lung biopsies from healthy individuals with no history of lung disease were investigated for the expression and presence of MK using in situ hybridization and immunohistochemistry. In the bronchi of large central airways, MK was detected in the columnar ciliated epithelial cells (fig. 1a, b, d, e). Incubations with a scrambled oligonucleotide and preimmune rabbit IgG, respectively, resulted in loss of labeling (fig. 1c, f). Low or no expression was seen in the epithelium of small airways (data not shown). In alveolar cells, the overall low presence of MK was seen, mainly on the apical surface (fig. $1 \mathrm{~g}$ ). In par- ticular, MK was detected in type 2 pneumocytes as judged by their cuboidal morphology (fig. 1g), and this was confirmed by colocalization with SP-A (fig. 1h). In induced sputum from apparently healthy individuals, $\mathrm{MK}$ was detected at a mean level of $105 \mathrm{pg} / \mathrm{ml}$ (range 95-116).

\section{Subcellular Distribution of $M K$ in Bronchial Epithelial Cells}

The distribution of MK was investigated on a subcellular level in bronchial epithelial cells using immunoelectron microscopy. In the bronchi, MK was detected in several compartments associated with bronchial epithelial cells (fig. 2). On the bronchial epithelial cell surface, MK was associated with cilia, the cell surface and also detected in mucus (fig. 2a-c). In addition, MK was detected in small intracellular vesicles of the cytoplasm that may represent export of de novo synthesized protein or pinocytosis. Intense labeling for MK was seen in the intercellular space between bronchial epithelial cells and in association with the basolateral cell membrane and basal membrane (fig. 2d, e).

In alveoli (fig. 2f), MK was detected on the surface of both type 1 and type 2 pneumocytes. On the epithelial cell surface, a thin layer that may represent the surfactant showed strong labeling for MK (fig. 2g). In type 2 pneumocytes, membrane ruffling with presence of MK was seen at sites of granule release, and an intragranular content of MK was also observed (fig. 2h).

\section{Antibacterial Activity of $M K$ against S. pneumoniae}

The bactericidal activity of MK against the important respiratory pathogen S. pneumoniae (strains A66 and TIGR4) was investigated using a viable count assay. MK showed a high bactericidal activity against both strains, and in the case of TIGR4, MK exerted a 10-fold higher bactericidal activity compared with the 'classical' antimicrobial peptide LL-37 (fig. 3a, b). To investigate the influence of sodium chloride on the bactericidal activity, MK $(1 \mu \mathrm{M})$ was compared with LL-37 $(1 \mu \mathrm{M})$ using the same viable count assay. MK and LL-37 both retained most of their bactericidal activity against $S$. pneumoniae (strain TIGR4) at increasing concentrations of sodium chloride (fig. 3c). To investigate the effect from MK with respect to the morphology of bacteria on an ultrastructural level, bacteria incubated in buffer or MK $(1 \mu \mathrm{M})$ were subject to SEM. This revealed a disturbed appearance, showing that MK caused blebbing and a disturbed integrity of the bacteria compared with bacteria incubated in buffer alone (fig. 3d, e). Thus, membrane-destabilizing properties of MK are likely of importance for the bactericidal activity [17]. 

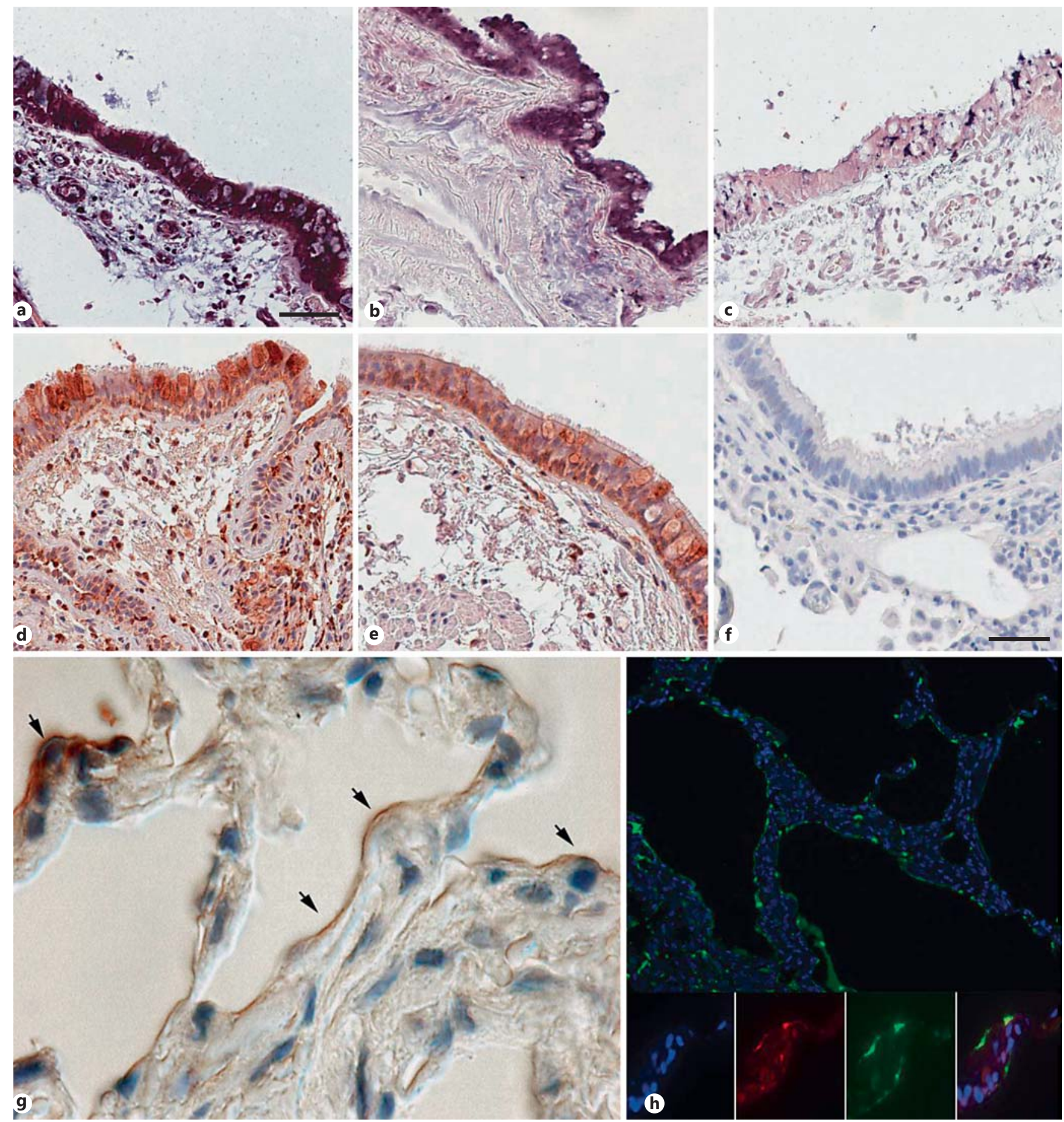

Fig. 1. Expression of MK in the airways of healthy individuals. Needle biopsies were obtained from the central airways of 8 individuals, and the results from two representative samples are shown. MK gene expression was detected by in situ hybridization, and bound oligonucleotides are visualized in blue/violet color. High expression of MK was detected in the columnar epithelial cells of the bronchi $(\mathbf{a}, \mathbf{b})$. In addition, some subepithelial cells showed expression of MK (a). Hybridization using a control oligonucleotide resulted in weak or no signal (c). Immunohistochemistry, using specific an- tibodies and a peroxidase reaction resulting in brownish staining, revealed the presence of $\mathrm{MK}$ in bronchial epithelial cells and in some subepithelial cells $(\mathbf{d}, \mathbf{e})$. $\mathbf{f}$ Staining with preimmune rabbit IgG is shown, resulting in loss of labeling. $\mathbf{g}$ In alveoli, MK is detected in the septa of the alveolar parenchyma, where arrows denote type 2 pneumocytes, having a characteristic cubic appearance. h Double staining for MK (red) and SP-A (green) in alveolar parenchyma shows colocalization of the molecules. The nuclei are stained by DAPI and appear blue. Scale bars: $50 \mu \mathrm{m}$ (a-e); $20 \mu \mathrm{m}$ (f). 
Fig. 2. Subcellular distribution of MK in airway epithelial cells. The distribution of MK was investigated using immunoelectron microscopy, and bound specific antibodies against MK are visualized by secondary antibodies conjugated with $10 \mathrm{~nm}$ colloidal gold particles. In large airways, MK was detected in several compartments associated with bronchial epithelial cells (a), cilia and mucus (b), cell surface (c), in the intercellular space (d), and basolaterally in association with the basal membrane (e). On the bronchial epithelial cell surface, MK was associated with cilia (arrowhead in a), in mucus (asterisk in a), and on the cell surface (arrowhead in c). In addition, MK was detected in small intracellular vesicles of the cytoplasm (arrows in c) that may represent the export of de novo synthesized protein or pinocytosis, enlarged in I. Intense labeling for MK was also seen in bodies present in the cytoplasm (arrow in d) and in the intercellular space between bronchial epithelial cells (arrowhead in $\mathbf{d}$, enlarged in II and III, respectively). In addition, strong labeling for MK was seen on the basal membrane (arrowheads in e enlarged in IV. In alveoli (f), MK was detected on the surface of both type 1 and type 2 pneumocytes. On the epithelial cell surface, a thin layer that may represent surfactant showed strong labeling for MK (arrowhead in $\mathbf{g}$ ) and also in intracellular vesicles (arrows in $\mathbf{g}$ ). In type 2 pneumocytes, membrane ruffling with the presence of MK was seen at sites of granule release (arrowhead) and an intragranular content of MK was also observed (arrows in $\mathbf{h}$ ). Scale bars: $5 \mu \mathrm{m}(\mathbf{a}, \mathbf{f}) ; 0.5 \mu \mathrm{m}$ (b-h); $0.1 \mu \mathrm{m}(\mathbf{I}-\mathbf{I V})$.
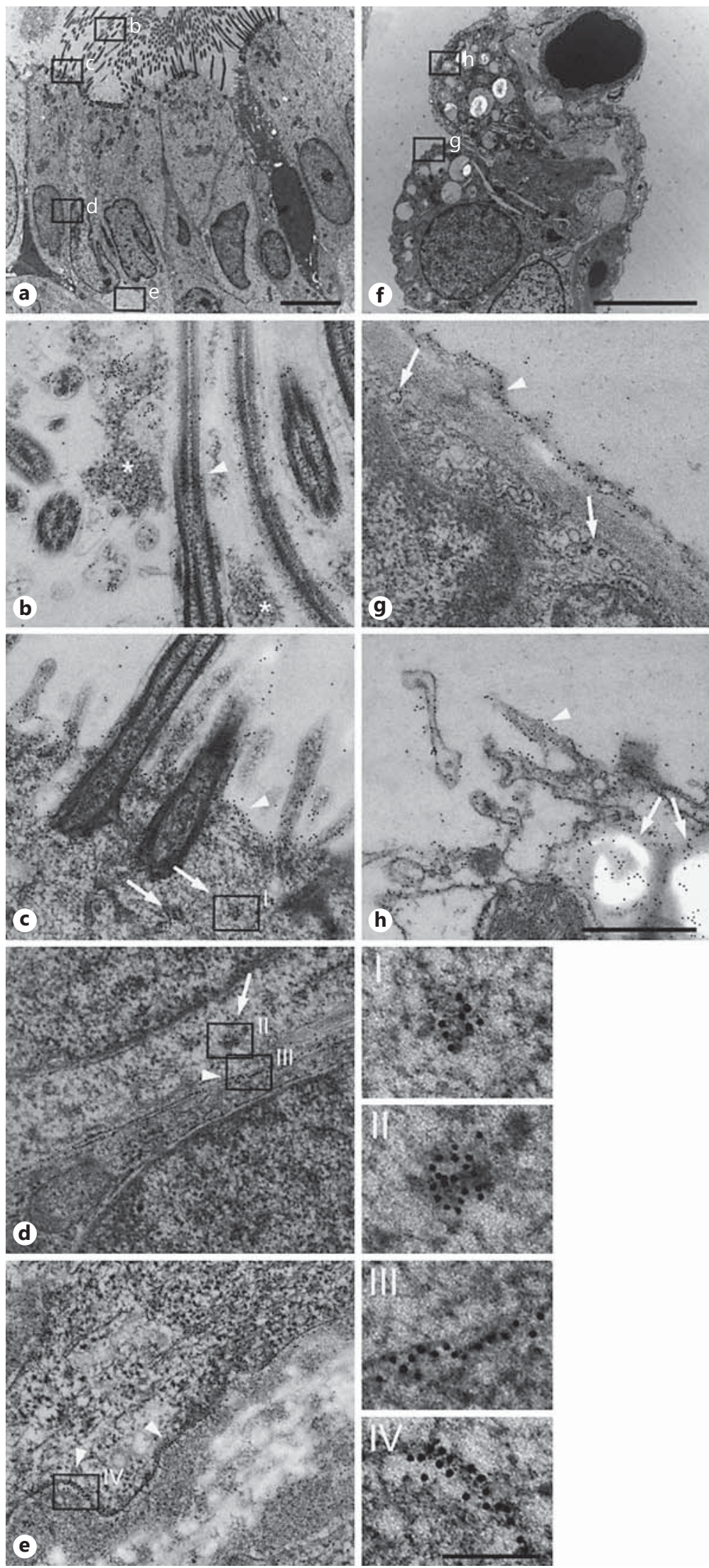

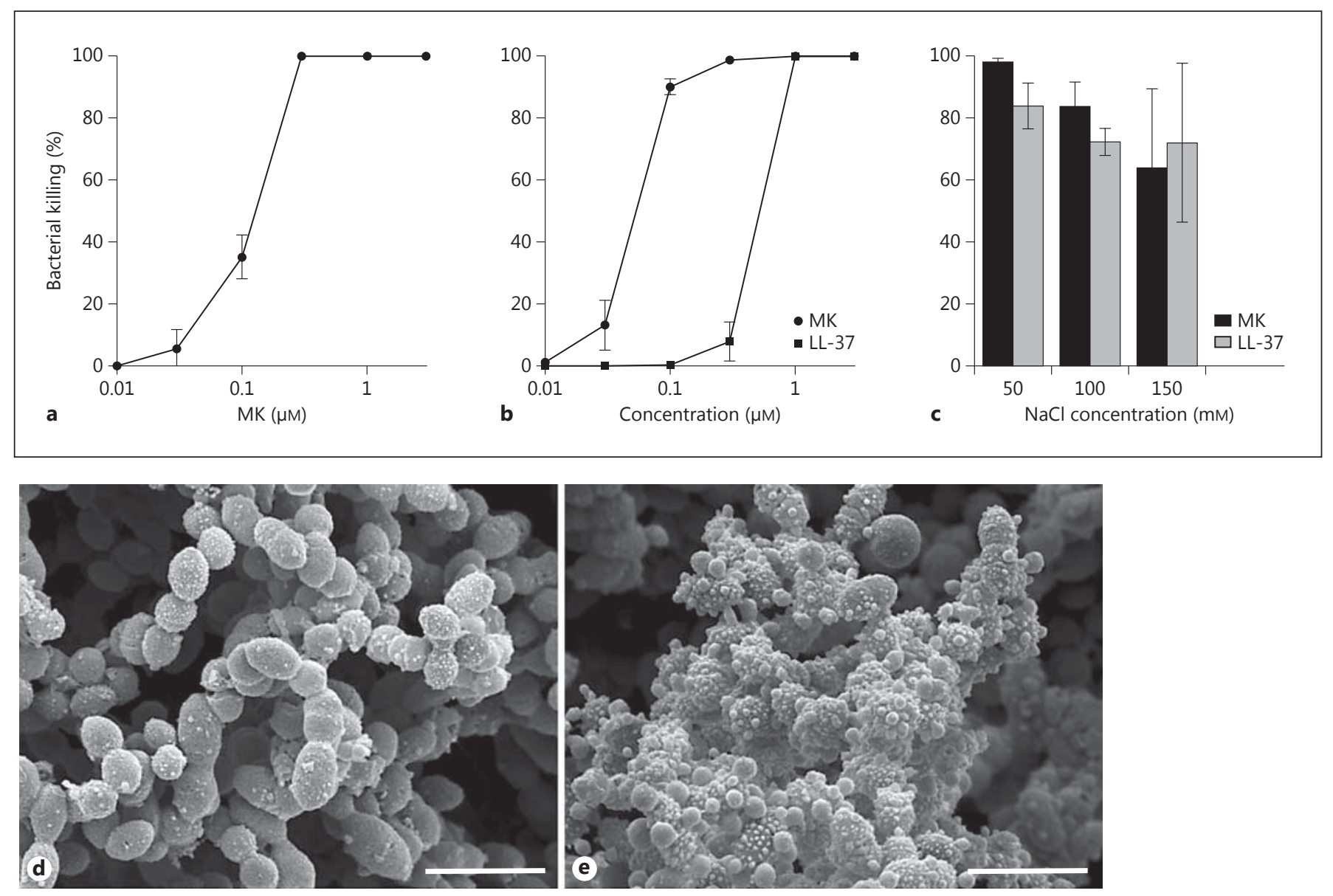

Fig. 3. Antibacterial activity of MK against S. pneumoniae. The bactericidal activity of MK against $S$. pneumoniae [the encapsulated strains of serotype 2 (A66) and serotype 3 (TIGR4)] was investigated using a viable count assay. MK or buffer alone was incubated with the bacteria at the concentrations indicated for $1 \mathrm{~h}$ at $37^{\circ} \mathrm{C}$. After plating on agar dishes overnight, the number of CFU was calculated and the percent bacterial killing calculated by comparison with the number of CFU when incubated in buffer alone. MK showed a high bactericidal activity against both strains, and in the case of TIGR4, MK exerted a 10-fold higher bactericidal activity compared with the 'classical' antimicrobial peptide LL-37 (a, b). To investigate the influence of sodium chloride on the bactericidal activity, MK $(1 \mu \mathrm{M})$ was compared with LL-37 $(1 \mu \mathrm{M})$ using the same viable count assay. MK and LL-37 both retained their bactericidal activity against $S$. pneumoniae (strain TIGR4) at increasing concentrations of sodium chloride (c). SEM showed that MK caused blebbing and disturbed the integrity of the bacteria (e), compared with bacteria appearing intact when incubated in buffer alone (d).

\section{Characterization of Bactericidal Activity in the}

Different Domains of $M K$

The folded NH2-terminal domain ( $\mathrm{N}$-domain, amino acids 21-81), the folded $\mathrm{COOH}$-domain (C-domain, amino acids 84-126) and the folded $\mathrm{COOH}$-terminal half of the molecule including the tail region (C-half, amino acids 82-143) were investigated for their antibacterial activity using the viable count assay (fig. 4). They all showed bactericidal activity against $S$. pneumoniae (strain TIGR4; fig. 4a-c). However, the $\mathrm{COOH}$-terminal half including the tail region (C-half) showed the highest activity (fig. 5c). The addition of the tail portion increases the net charge and isoelectric point of the C-domain, which likely explain the high bactericidal activity of this segment of the molecule.

\section{Production of MK by Airway Epithelial Cells in vitro and MK Contribution to Bactericidal Activity of Air Surface Liquid \\ Primary HBEC were cultured in ALI for 4 weeks to al-} low differentiation, in the absence of antibiotics. The medium was changed and the apical side rinsed with buffer; 

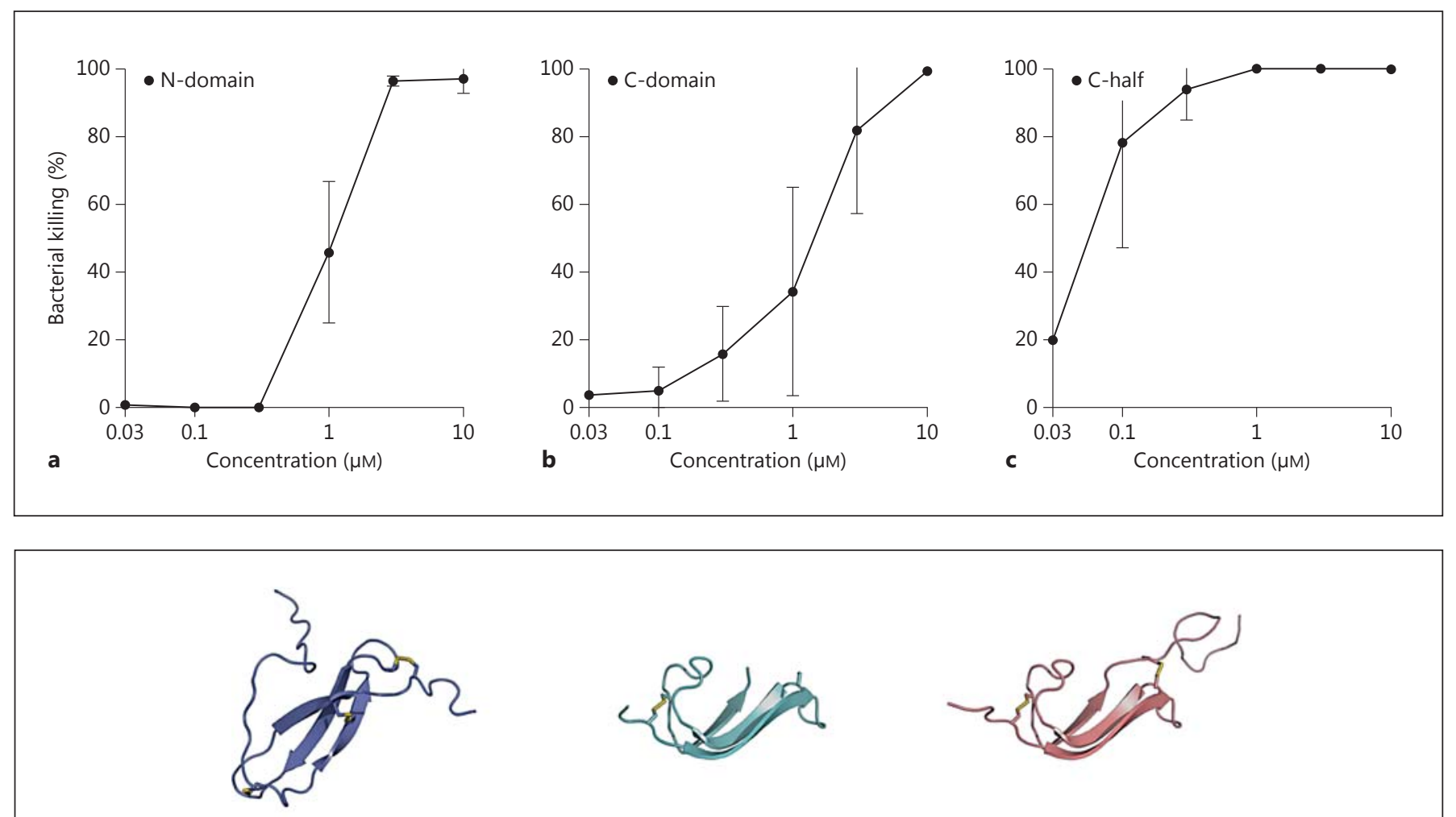

$\mathrm{N}$-domain

C-domain

C-half

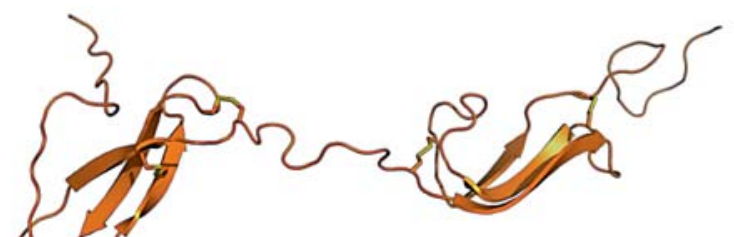

MK holoprotein

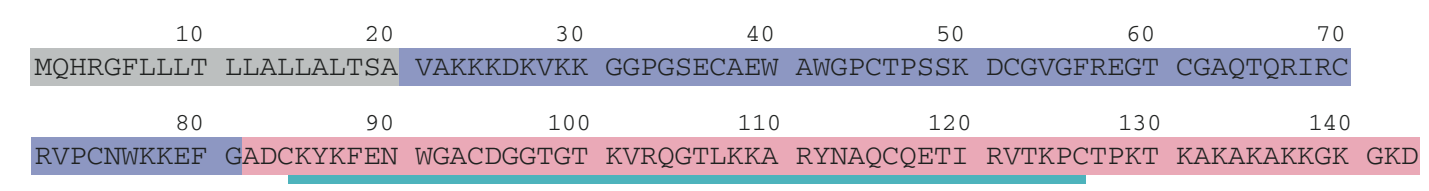

d

\begin{tabular}{|l|c|c|c|c|}
\hline \multicolumn{2}{|c}{ MK holoprotein } & N-domain & C-domain & C-half \\
\hline No. amino acids & 123 & 61 & 43 & 62 \\
\hline MW (Da) & 13,421 & $6,645.6$ & $4,839.5$ & $6,792.8$ \\
\hline pl & 9.78 & 9.38 & 9.51 & 9.93 \\
\hline Net change & +19 & +7 & +6 & +12 \\
\hline
\end{tabular}

Fig. 4. Characterization of bactericidal activity in the different domains of MK. The folded NH2-terminal domain (N-domain, amino acids 21-81; model and marked sequence in violet), the folded $\mathrm{COOH}$-terminal domain (C-domain, amino acids 84-126; model and marked sequence in turquoise) and the folded $\mathrm{COOH}$-terminal half of the molecule including the tail-region (C-half, amino acids 82-143; model and marked sequence in magenta), described in d, were investigated for their antibacterial activity using the viable count assay. In the cases of all three variants, bactericidal activity against $S$. pneumoniae (strain TIGR4) was seen (a-c). However, the $\mathrm{COOH}$-terminal half including the tail-region (C-half) showed the highest activity (c). As indicated in the table (bottom) the $\mathrm{COOH}$-terminal of the molecule has the highest net charge and isoelectric point $(\mathrm{pI})$. 
the cells were incubated for another $24 \mathrm{~h}$, whereafter the medium was collected and the apical surface was rinsed with buffer. As recovered in the apical rinsing fluid and basolateral release to the underlying medium, approximately one fifth of the MK produced was released apically (fig. 5a). Primary HAEpiC, primary HBEC, the bronchial epithelial cell lines BEAS-2B and 16-HBE, and the alveolar epithelial cell line A549 were grown to near confluence in a flask. The cell medium was changed and the cells incubated for $72 \mathrm{~h}$, the medium collected and the MK content determined by ELISA. In particular the HAEpiC produced relatively high quantities of MK while no MK could be detected in the medium from the A549 cell line (data not shown). When cultured in flasks, immersed in medium, primary HBEC and the bronchial epithelial cell line BEAS-2B produced relatively low amounts of $\mathrm{MK}$ while the $16-\mathrm{HBE}$ cell line produced higher amounts (fig. 5b). No MK could be detected in medium that had not been incubated with cells.

To investigate possible bactericidal activity in the air surface liquid, HBEC were grown to confluence and allowed to differentiate using the ALI system in the presence of RA. After removal of mucus, the apical surface was rinsed with buffer that was subsequently incubated with S. pneumoniae (strain TIGR4). One part was used for the viable count assay and one part was processed for SEM. Bacteria incubated with the rinsing fluid showed blebbing and disturbed integrity, similar to bacteria incubated with MK (fig. 5c, d). To determine whether MK contributes to the bactericidal activity of the rinsing fluid, MK was immunoprecipitated from one portion of the rinsing fluid while another portion was immunoprecipitated using control antibodies. Thereafter, the rinsing fluids were used to investigate bactericidal activity against $S$. pneumoniae (strain TIGR4), using the viable count assay. The rinsing fluids were diluted 1:2 with buffer, and at that dilution, the rinsing fluid depleted of MK showed significantly lower bactericidal activity compared with the rinsing fluid that had been immunoprecipitated with control antibodies, suggesting that MK constitutes a significant part of the bactericidal activity in airway surface liquid, at least in vitro (fig. 5e).

\section{Discussion}

In this study, we show that bronchial epithelial cells in vivo constitutively express the antimicrobial growth factor MK. In addition, MK shows bactericidal activity against the common respiratory pathogen $S$. pneumoni-

Midkine Production by Airway

Epithelium ae. In vitro, RA-differentiated bronchial epithelial cells release bactericidal activity that is partly dependent on MK. In addition to being an important growth factor during embryogenesis, MK shows both constitutive and inflammation-dependent expression in many tissues, not least in epithelial tissue, of the adult [16]. In contrast, the expression of pleiotrophin appears more limited to embryogenesis and neoplastic tissue [16]. In mice, MK is expressed in the bronchial epithelial cells during embryoegenesis but not constitutively in adult mice [25]. Thus, MK null mice could not be used to explore a potential role during infection. However, expression is induced in bronchial epithelial cells by hypoxia, involving the transcription factor hypoxia-inducible factor- $1 \alpha$ and possibly also by oxidative stress $[26,27]$. The presence of MK in bronchial epithelium of large airways in biopsies from healthy individuals suggests that MK gene regulation is subject to different regulation in humans compared with mice. In addition to hypoxia-inducible factor-1 $\alpha$ - and RA-responsive elements in the promoter region of the MK gene, the expression is enhanced by nuclear factor- $\mathrm{\kappa B}$ [28]. As a consequence, increased expression may be seen during inflammatory responses in the airways. However, in our study, using RA-differentiated HBEC in the air liquid system, only a weak increase in the production of MK was seen after stimulation with proinflammatory cytokines such as interleukin- $1 \beta$ or interferon- $\gamma$, and no effects from tumor necrosis factor or interleukin-4, suggesting that the presence of RA is the main regulator of the high transcriptional activity seen in vitro (data not shown). Interestingly, primary pneumocytes showed the highest MK production of the airway epithelial cells when cultured in vitro, while the cell line A549, which is derived from a carcinoma originating from type 2 pneumocytes, did not display any detectable MK production. Serum levels of MK are explored to be used as a marker for tumor burden in various malignancies, including lung cancer [29]. However, a large variation in the MK levels are observed and may depend on the degree of differentiation, which may also be reflected in the case of A549. The most abundant AMPs that are constitutively produced and present in the air surface liquid are lysozyme, lactoferrin and secretory leukocyte proteinase inhibitor. The proteins are present at approximately $1-10 \mu \mathrm{g} / \mathrm{ml}$ in air surface liquid $[5,6,30]$. Other AMPs include $\beta$-defensins (hBD) and LL-37 [7-9, 11]. HBD-2 expression is induced by inflammation, whereas HBD-1 may serve as a defense in the absence of inflammation [31]. The concentrations of these in the airway surface liquid are not precisely 

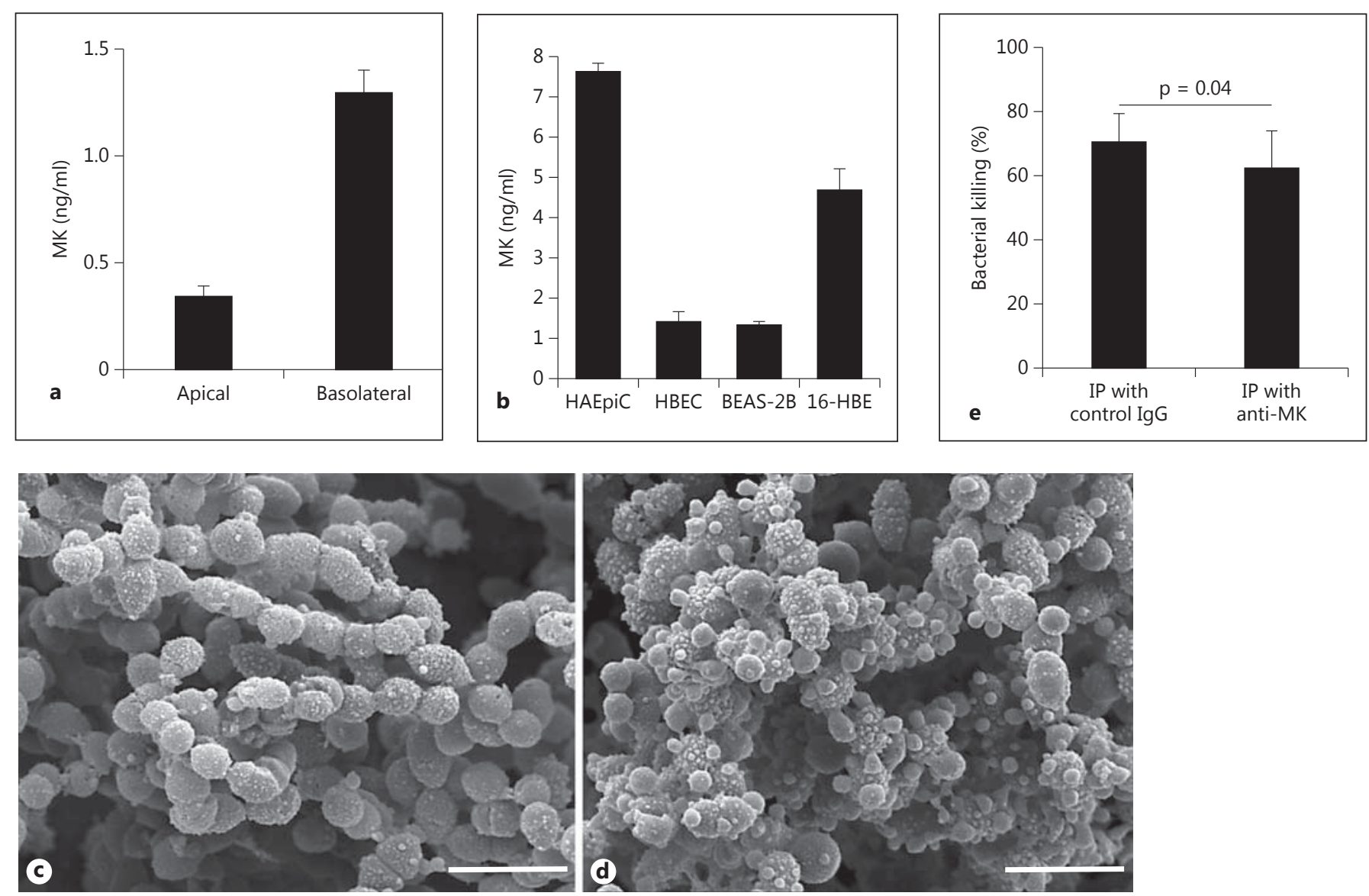

Fig. 5. Production of MK by airway epithelial cells in vitro and contribution to bactericidal activity of the air surface liquid. a Primary HBEC were cultured in an ALI for 4 weeks to allow differentiation, in the absence of antibiotics. The medium was changed, the apical side rinsed with buffer, and the cells were incubated for another $24 \mathrm{~h}$, whereafter the underlying medium was collected and the apical surface was rinsed with buffer. The amount of MK was determined by ELISA and the results shown represent the mean and SD from three separate experiments. b HAEpiC, primary HBEC, the bronchial epithelial cell lines BEAS-2B and 16-HBE, and the alveolar epithelial cell line A549 were grown to near confluence in a flask. The cell medium was changed and the cells incubated for $72 \mathrm{~h}$, the medium collected and the MK content determined by ELISA. No MK could be detected in the medium from the A549 cell line (data not shown). The results represent the mean and SD from three different incubations. c, d To investigate possible bactericidal activity in the air surface liquid, HBEC were grown to confluence and allowed to differentiate using the air- liquid system in the presence of RA. After removal of mucus, the apical surface was rinsed with buffer which was incubated with $S$. pneumoniae (strain TIGR4). One part was used for the viable count assay and one part was processed for SEM. Bacteria incubated with the rinsing fluid show blebbing and disturbed integrity (d), compared with bacteria incubated in buffer alone (c). e To determine whether MK contributes to the bactericidal activity of the rinsing fluid, MK was immunoprecipitated from one portion of the rinsing fluid while another portion was immunoprecipitated using control antibodies. Thereafter, the rinsing fluids were used to investigate bactericidal activity against $S$. pneumoniae (strain TIGR4), using the viable count assay. The rinsing fluid depleted of MK showed significantly lower bactericidal activity compared with the rinsing fluid that had been immunoprecipitated with control antibodies, suggesting that MK constitutes a significant part of the bactericidal activity in airway surface liquid. Statistical significance was determined using Student's t test for paired observations. IP = Immunoprecipitation. known, but the $\beta$-defensins HBD- 1 and HBD-2 are present at levels about 1,000-fold lower than lysozyme [30, 31]. Assuming that the air surface liquid layer is approximately $20 \mu \mathrm{m}$, the MK concentrations detected in the rinsing fluid obtained from the apical surface in vitro would be approximately $0.7 \mu \mathrm{M}$, i.e. a bactericidal concentration. Lysozyme is a muramidase degrading cell wall components of bacteria. Interestingly, lysozyme displays synergistic bactericidal activity in combination with $\beta$-defensins [32]. However, we did not find syner- 
gistic bactericidal activity when combined with $\mathrm{MK}$ (data not shown). Depleting MK by immunoprecipitation gave a small but significant reduction in the bactericidal activity. However, given the plethora of additional AMPs present, there is likely a high degree of redundancy, also implicating the importance of this arm of host defense. It is common that AMPs share the properties of growth factors and chemokines [7]. MK fits into this pattern, having potent antibacterial properties, acting as a growth factor and possessing chemotactic properties against neutrophils $[16,33]$. However, since there is no significant influx of neutrophils to the airways during noninflammatory conditions, it is likely that the chemotactic or chemokinetic activity of MK appears in conjunction with other factors. Most hitherto characterized AMPs are sensitive to the presence of salt. The salt concentration of air surface liquid in health and disease (i.e. cystic fibrosis) has been subject to debate [34]. In previous reports, this thin layer of approximately $20 \mu \mathrm{m}$ has been shown to contain $50 \pm 4 \mathrm{mM}$ for $[\mathrm{Na}+]$ and $37 \pm$ $6 \mathrm{mM}$ for [Cl-]. In contrast, the air surface liquid in cystic fibrosis epithelia had $[\mathrm{Na}+]$ and $[\mathrm{Cl}-]$ concentrations and was shown to contain approximately two times these values [35]. A recent study in a porcine model of cystic fibrosis indicates that the sodium content is similar in air surface liquid of healthy animals and in those with a CFTR mutation, with a $\mathrm{Na}^{+}$content reaching 150 $\mathrm{mM}$ [36]. Using immunoelectron microscopy, MK appeared surface associated in bronchial epithelial cells.
MK has heparin-binding properties and it is likely that the molecule is bound to glycosaminoglycans on the cell surface. Oligomerization may be a way to achieve both binding and having regions free to interact with invading bacteria. This would be an economical mean for the cell to retain an antimicrobial gradient close to the cellular barrier. In addition to MK expression, several other components of airway innate immunity are dependent on RA, such as the mucociliary system and the production of surfactant proteins [15, 37-39]. Therefore, several clinical studies have tried supplementation of vitamin A for patients with low levels of the vitamin and suffering from pneumonia. However, a meta-analysis has failed to show any effect from the addition of vitamin A [40]. Taken together, the findings of the present study suggest that $\mathrm{MK}$ is part of the constitutive host defense, present in the airways during normal, noninflammatory conditions.

\section{Acknowledgments}

We wish to express our sincere gratitude to Pia Andersson, Maria Baumgarten and Christina Möller for their skillful technical assistance and Dr. Björn Walse for the molecular models. This work was supported by grants from the Swedish Research Council (No. 2010-4224), the Swedish Heart and Lung Foundation (No. 20100164), the Medical Faculty at Lund University, the Swedish Government Funds for Clinical Research, the Foundations of Bergh, Greta \& Johan Kock, and Alfred Österlund.

\section{References}

1 Thorne PS, Kiekhaefer MS, Whitten P, Donham KJ: Comparison of bioaerosol sampling methods in barns housing swine. Appl Env Microbiol 1992;58:2543-2551.

2 Bartlett JA, Fischer AJ, McCray PB Jr: Innate immune functions of the airway epithelium. Contrib Microbiol 2008;15:147-163.

3 Fleming A: Observations on a bacteriolytic substance ('lysozyme') found in secretions and tissues. Br J Exp Pathol 1922;3:252-260.

-4 Hiemstra PS, Maassen RJ, Stolk J, HeinzelWieland R, Steffens GJ, Dijkman JH: Antibacterial activity of antileukoprotease. Infect Immun 1996;64:4520-4524.

5 Thompson AB, Bohling T, Payvandi F, Rennard SI: Lower respiratory tract lactoferrin and lysozyme arise primarily in the airways and are elevated in association with chronic bronchitis. J Lab Clin Med 1990;115:148158.
6 Vogelmeier C, Hubbard RC, Fells GA, Schnebli HP, Thompson RC, Fritz H, Crystal RG: Anti-neutrophil elastase defense of the normal human respiratory epithelial surface provided by the secretory leukoprotease inhibitor. J Clin Invest 1991;87:482-488.

7 Kolls JK, McCray PB Jr, Chan YR: Cytokinemediated regulation of antimicrobial proteins. Nature Rev Immunol 2008;8:829-835.

-8 Bals R, Wang X, Wu Z, Freeman T, Bafna V, Zasloff M, Wilson JM: Human beta-defensin 2 is a salt-sensitive peptide antibiotic expressed in human lung. J Clin Invest 1998; 102:874-880.

-9 Bals R, Wang X, Zasloff M, Wilson JM: The peptide antibiotic LL-37/hCAP-18 is expressed in epithelia of the human lung where it has broad antimicrobial activity at the airway surface. Proc Natl Acad Sci USA 1998;95: 9541-9546.
10 Goldman MJ, Anderson GM, Stolzenberg ED, Kari UP, Zasloff M, Wilson JM: Human beta-defensin-1 is a salt-sensitive antibiotic in lung that is inactivated in cystic fibrosis. Cell 1997;88:553-560.

11 Kao CY, Chen Y, Thai P, Wachi S, Huang F, Kim C, Harper RW, Wu R: IL-17 markedly up-regulates beta-defensin-2 expression in human airway epithelium via JAK and NFkappaB signaling pathways. J Immunol 2004; 173:3482-3491.

12 McCray PB Jr, Bentley L: Human airway epithelia express a beta-defensin. Am J Respir Cell Mol Biol 1997;16:343-349.

13 O’Brien KL, Wolfson LJ, Watt JP, Henkle E, Deloria-Knoll M, McCall N, Lee E, Mulholland $\mathrm{K}$, Levine OS, Cherian T: Burden of disease caused by Streptococcus pneumoniae in children younger than 5 years: global estimates. Lancet 2009;374:893-902. 
14 Wolbach SB, Howe PR: Tissue changes following deprivation of fat-soluble A vitamin. J Exp Med 1925;42:753-777.

15 Chytil F: Retinoids in lung development. FASEB J 1996;10:986-992.

16 Muramatsu T: Midkine and pleiotrophin: two related proteins involved in development, survival, inflammation and tumorigenesis. J Biochem 2002;132:359-371.

-17 Svensson SL, Pasupuleti M, Walse B, Malmsten M, Mörgelin M, Sjögren C, Olin AI, Collin M, Schmidtchen A, Palmer R, Egesten A: Midkine and pleiotrophin have bactericidal properties: preserved antibacterial activity in a family of heparin-binding growth factors during evolution. J Biol Chem 2010;285 16105-16115.

18 Fabri L, Maruta H, Muramatsu H, Muramatsu T, Simpson RJ, Burgess AW, Nice EC: Structural characterisation of native and recombinant forms of the neurotrophic cytokine MK. J Chromatogr 1993;646:213-225.

-19 Yan WK, Goette M, Hofmann G, Zaror I, Sim J: High-level soluble expression, purification and characterization of active human midkine from Escherichia coli. Protein Expr Purif 2010;70:270-276.

20 Inui T, Bodi J, Kubo S, Nishio H, Kimura T, Kojima S, Maruta H, Muramatsu T, Sakakibara S: Solution synthesis of human midkine, a novel heparin-binding neurotrophic factor consisting of 121 amino acid residues with five disulphide bonds. J Pept Sci 1996;2:2839.

-21 Kojima S, Inui T, Kimura T, Sakakibara S, Muramatsu $\mathrm{H}$, Amanuma $\mathrm{H}$, Maruta $\mathrm{H}, \mathrm{Mu}-$ ramatsu T: Synthetic peptides derived from midkine enhance plasminogen activator activity in bovine aortic endothelial cells. Biochem Biophys Res Commun 1995;206:468473.

22 Jiborn T, Abrahamson M, Wallin H, Malm J, Lundwall A, Gadaleanu V, Abrahamsson PA, Bjartell A: Cystatin C is highly expressed in the human male reproductive system. J Androl 2004;25:564-572.
23 Bengtson SH, Eddleston J, Mörgelin M, Zuraw BL, Herwald H: Regulation of kinin $\mathrm{B}(2)$ receptors by bradykinin in human lung cells. Biol Chem 2008;389:1435-1440.

24 Bober M, Enochsson C, Collin M, Mörgelin M: Collagen VI is a subepithelial adhesive target for human respiratory tract pathogens. J Innate Immun 2010;2:160-166.

25 Reynolds PR, Mucenski ML, Whitsett JA: Thyroid transcription factor (TTF)-1 regulates the expression of midkine (MK) during lung morphogenesis. Dev Dyn 2003;227:227237.

26 Reynolds PR, Mucenski ML, Le Cras TD Nichols WC, Whitsett JA: Midkine is regulated by hypoxia and causes pulmonary vascular remodeling. J Biol Chem 2004;279: 37124-37132.

27 Hobo A, Yuzawa Y, Kosugi T, Kato N, Asai N, Sato W, Maruyama S, Ito Y, Kobori H, Ikematsu S, Nishiyama A, Matsuo S, Kadomatsu $\mathrm{K}$ : The growth factor midkine regulates the renin-angiotensin system in mice. J Clin Invest 2009;119:1616-1625.

28 You Z, Dong Y, Kong X, Beckett LA, Gandour-Edwards R, Melamed J: Midkine is a NF-kappaB-inducible gene that supports prostate cancer cell survival. BMC Med Genomics 2008; $1: 6$

29 Ikematsu S, Yano A, Aridome K, Kikuchi M, Kumai H, Nagano H, Okamoto K, Oda M, Sakuma S, Aikou T, Muramatsu H, Kadomatsu K, Muramatsu T: Serum midkine levels are increased in patients with various types of carcinomas. Br J Cancer 2000;83:701-706.

- 30 Singh PK, Jia HP, Wiles K, Hesselberth J, Liu L, Conway BA, Greenberg EP, Valore EV, Welsh MJ, Ganz T, Tack BF, McCray PB Jr: Production of beta-defensins by human airway epithelia. Proc Natl Acad Sci USA 1998; 95:14961-14966.

31 Travis SM, Conway BA, Zabner J, Smith JJ, Anderson NN, Singh PK, Greenberg EP, Welsh MJ: Activity of abundant antimicrobials of the human airway. Am J Respir Cell Mol Biol 1999;20:872-879.
2 Singh PK, Tack BF, McCray PB Jr, Welsh MJ: Synergistic and additive killing by antimicrobial factors found in human airway surface liquid. Am J Physiol Lung Cell Mol Physiol 2000;279:L799-L805.

33 Takada T, Toriyama K, Muramatsu H, Song, XJ, Torii S, Muramatsu T: Midkine, a retinoic acid-inducible heparin-binding cytokine in inflammatory responses: chemotactic activity to neutrophils and association with inflammatory synovitis. J Biochem 1997;122:453-458.

34 Guggino WB: Cystic fibrosis and the salt controversy. Cell 1999;96:607-610.

35 Joris L, Dab I, Quinton PM: Elemental composition of human airway surface fluid in healthy and diseased airways. Am Rev Respir Dis 1993;148:1633-1637.

-36 Pezzulo AA, Tang XX, Hoegger MJ, Alaiwa $\mathrm{MH}$, Ramachandran S, Moninger TO, Karp PH, Wohlford-Lenane CL, Haagsman HP, van Eijk M, Bánfi B, Horswill AR, Stoltz DA, McCray PB Jr, Welsh MJ, Zabner J: Reduced airway surface $\mathrm{pH}$ impairs bacterial killing in the porcine cystic fibrosis lung. Nature 2012; 487:109-113.

37 Bernacki SH, Nelson AL, Abdullah L, Sheehan JK, Harris A, Davis CW, Randell SH: Mucin gene expression during differentiation of human airway epithelia in vitro. Muc4 and muc5b are strongly induced. Am J Respir Cell Mol Biol 1999;20:595-604.

38 de Jong PM, van Sterkenburg MA, Hesseling SC, Kempenaar JA, Mulder AA, Mommaas AM, Dijkman JH, Ponec M: Ciliogenesis in human bronchial epithelial cells cultured at the air-liquid interface. Am J Respir Cell Mol Biol 1994; 10:271-277.

39 Koo JS, Yoon JH, Gray T, Norford D, Jetten AM, Nettesheim P: Restoration of the mucous phenotype by retinoic acid in retinoid-deficient human bronchial cell cultures: changes in mucin gene expression. Am J Respir Cell Mol Biol 1999;20:43-52.

$40 \mathrm{Ni}$ J, Wei J, Wu T: Vitamin A for non-measles pneumonia in children. Cochrane Database Syst Rev 2005:CD003700. 